\title{
Workforce diversity and management: An emphirical study on relationship between diversity management practices, obstacles and acceptance of gender diversity among employees in IT industry; Bangalore
}

\author{
Shreelatha R. Rao ${ }^{1}$, Dr. M. M. Bagali ${ }^{2}$ \\ ${ }^{1}$ Research Scholar, Management Education, JAIN University, Bangalore \\ ${ }^{2}$ Professor of HR, Coordinator, Research in Management, JAIN University, CMS Business School, and guide, \\ Jain University
}

\begin{abstract}
Advances in technology and the advent of a global economy bring the people of the world closer together than ever before. Given this fact, businesses, educational systems and other entities are investigating ways to better recruit their workforce by attracting and retaining the best and most qualified workers. Diversity inclusion and managing diversity are becoming strategic issues for the multinational companies throughout the world. Diversity Management is a process intended to create and maintain a positive work environment where the similarities and differences of individuals are valued. As Information Technology (IT) ${ }^{1}$ industry needs talent from throughout the world, it has accepted diversity in workforce and successfully reaping the benefits of workforce diversity. Bangalore is the IT hub of India and companies show much wider variety of workforce diversity at the organizational level. Around 30\% to 32\% of the female workforce has been recruited by IT organizations and it is the major recruiter of women workforce in India. This paper examines the acceptance of gender diversity among employees and how the impact of diversity management programs and practices has taken by different IT companies, and also investigates influence of obstacles present in IT industry. The population for the study consists of employees from Information Technology firms including IT services companies and ITES-BPO companies ${ }^{2}$ situated at Bangalore. With the help of focus group interview and discussions with HR managers of reputed companies, questionnaire was developed by the researcher. A pilot study was conducted by considering the responses of 100 employees. The developed tool was found to be reliable by getting Cronbach's alpha values for the variables structured in questionnaire.
\end{abstract}

Key words: gender diversity, diversity management programs and practices, obstacles, IT industry.

\section{Introduction}

Workforce diversity has become an important issue in today's organizations, as they are becoming increasingly diverse with respect to their workforce. Diversity exists in an organization when its members differ from one another along one or more important dimensions (Thomas and Ely, 2001). If everyone in the organization is exactly like everyone else, no diversity exists. But everyone is different along every imaginable dimension, total diversity exists. In reality, of course, these extremes are more hypothetical than real; most settings are characterized by level of diversity somewhere between. Thus, diversity is not an absolute phenomenon wherein a organization is or is not diverse. Instead, diversity should be conceptualized as a continuum. Therefore, diversity should be thought of in terms of degree or level of diversity along relevant dimensions (Dora and Keith, 1998). In business terms, diversity can be defined as a set of differences of individual traits including socio demographic variables and professional variables, which can be found in an organization's various levels (Cox, 1991; Thomas, 1991). Core dimensions of diversity include age, ethnicity and culture, gender, race, religion, sexual orientation, and capabilities (Das, and Wagar, 2007). Secondary dimensions include education, status, language, income levels, etc. Diverse workforce (diversity) refers to the co-existence of people from various socio-cultural backgrounds within the company. Diversity includes factors such as race, gender, age, colour, physical ability, ethnicity, etc. (Kundu and Turan, 1999). Diversity has a fairly wide connotation and could include everything from age, culture, gender, race, religion and even thought. Typically, diversity refers to the demographic description of the people working for an organization and human

\footnotetext{
${ }^{1}$ IT industry refers to all type of Information Technology Services industry, including all types of software, hardware, enabled services, and Business Process Outsourcing industries.

${ }^{2}$ ITES-BPO is a major constituent of IT industry in India. ITES-BPO means Information Technology Enabled Services with Business Process Outsourcing units.
} 
resource policies to correct gender and other imbalances. Most of the multinational companies, both IT and non IT companies, have consciously practiced and experienced the benefits of practicing diversity (Dataquest, $2006)^{3}$.

Accepting the differences in gender is of great importance because in modern organizations, people work in teams to achieve organizational effectiveness. Especially in IT companies, team based project works are very commonly seen in performing organizational tasks. Dynamic companies in the field of IT Industry look for talent and skill irrespective of their differences in culture and gender. The organizations which fail to embrace diversity and do not adopt holistic approach to eliminate discrimination and injustice will adversely affect both employees, customers (Khandelwal, 2002).

Interest in diversity and diversity management and implications of diversity is growing in the academic communities and the business (O'leary and Weathington (2006). Numerous companies have discovered increasing the diversity of their workforce pays off in terms of improved performance, happier customers and more satisfied employees (Dobbs, 1998; Kochan, T et al., 2003). Demographics, competition for talent, marketplace demands and the changing environment call for a diverse workforce. This workforce includes men and women, employees with different backgrounds, younger and older workers, physically challenged workers and other employees who differ from one another. By bringing a greater pool of talent to the workforce, diversity often results with better decision making, better task performance work motivation and knowledge sharing among employees.

Gender diversity is the most recognized form of diversity in Indian IT companies and organizations are making constructive efforts to create an environment of gender diversity inclusiveness in IT industry (Dataquest, 2006). Women represent the main economic force in most of the developing countries. Standing at approximately $50 \%$ of the population, the focus on women as valuable group of talent to attract and retain is the subject of strategic discussions in the organizations. As economies become more and more information-driven, the issues of women's access to and use of ITs is growing in importance for both developed and developing economies. The ease with which information and communication technologies can transmit and disseminate information for development is well recognized.

Organizations are framing different diversity management strategies to make effective use of the talent of female employees in organizations. But at the same time, several obstacles are prevailing in IT industry, which have negative impact on gender diversity. .

Workplaces in IT companies today are highly diversified with the employees of different background. People from various countries and societies bring varied culture to the workplace. The increasing diversity among the employees in information technology industry is a reflection of increasing educational facilities and increasing educational levels of people in various developing countries, social change, social shifts of various regional groups, career orientation among women, increasing aspirations for work and career. This is more visible in India after 1990s due to enhancement of career opportunities for women. Organizations, while recruiting, try to maintain a balance between male and female workers, creating a culture of comfort and compelling place to perform. This is not certainly for the opposite gender appeal in the workplace, rather it is more for replicating a culture of global talent, mutual cooperation and support. While it is important to accept and respect the socialized role expectations and subsequent choices men and women make, there is merit in organizations working more proactively to create structures, policies and a culture that is sensitive to the differing needs of women. The uptrend in percentage of women in IT industry has been depicted through graphical presentation in graph 1.1

Graph 1.1: Percentage of women in Indian IT industry

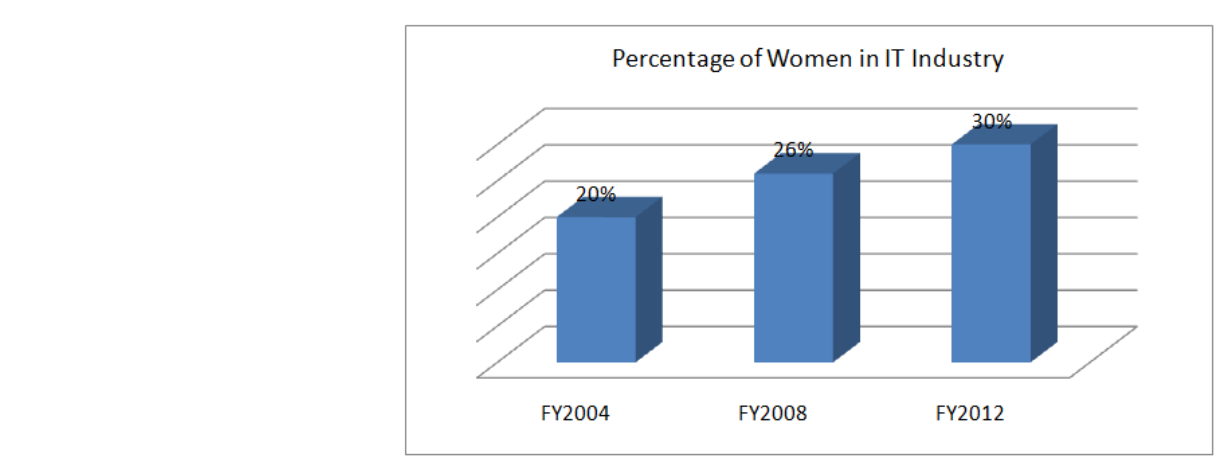

Source: NASSCOM Strategic Review, 2012

\footnotetext{
3 Dataquest is an IT journal. This information has been collected from the article "The Potpouri Workforce", by Bhaswathy Chakravarthy, Dataquest, dated November 08, 2006.
} 
This shows the percentage of women in IT industry is in uptrend and there is an increase of women percentage from $20 \%$ in FY2004 to 30\% in FY2012 (NASSCOM Strategic Review, 2012).

The IT and ITES-BPO sector introduced secure working atmosphere, higher salaries, gender neutral policies, free pick-up and drop off facility to home, part time and flexible time, as well as flexible career policies. All these efforts made IT industry as a favorable destination for women to work. Infosys, for instance, built a satellite office in Bangalore for pregnant women and young mothers to spare them to commute to the main office on the outskirts of the city The Indian IT industry is a major player of gender diversity. According to Dataquest ${ }^{4}$, the Indian top companies have $25 \%$ to $35 \%$ of women workforce and have different kinds of diversity programs based on the need and suitability.

\subsection{Need and significance of the study}

The Indian information technology industry is playing a key role in putting India on the global map. The merits of the workforce diversity has been debated everywhere throughout the world. Workforce diversity and management is on the emerging trend in Indian organizations. Diversity Management has already begun in the Indian IT industry and numerous companies have multiple locations abroad and are realizing the need to develop a global workforce. The need of the talent mix pressurizing the employers of IT companies to attract and to retain diverse workforce. Employers are being urged to embrace diversity and advised against neglecting it. Management scholars warn that while organizations may run the risk of losing their competitive advantage and innovativeness by failing to effectively utilize and manage diversity. The projected changes in organizational demographics combined with employers' concerns about motivating and obtaining satisfactory levels of performance from a diverse group of employees has created an urgency to understand and recognize the value of diversity in all organizations. IT industry is one of the major industries in India, which has embraced workforce diversity as a strategy to remain competitive, innovative and productive in the face of changing demographics and the rapid globalization of business. $\mathrm{NASSCOM}^{5}$, an IT lobbying body, has announced the diversity awards for the IT companies in India, which are doing best in the area of workforce diversity. The acceptance of the gender diversity will be effected by the diversity management practices and programs initiated at organizations. Several obstacles to diversity also influence the acceptance of diversity among employees in workplaces. There are several researches arguing the benefits of workforce diversity in organizations. Cox and Blake (1991) argued that diversity can be a source of competitive advantage. However, theories and empirical research thus far suggest that diversity can lead to either positive outcome. The resourcebased view of the firm (Barney, 2001) also suggests a positive diversity-performance relationship.

\subsection{Literature Review}

Bhatnagar, D. (1987) in her research, investigates about attitudes towards women managers in banks. Data were collected from 65 female and 136 male employees working at clerical, junior, middle and senior middle management levels in banks. Results reveal a widespread lukewarm attitude towards women managers. Though women hold a much more favorable attitude than men, female responses are not equivalently positive. The research identifies great differences in attitudes of male and female employees towards the females in managerial positions. Author identifies the resistance of the men in accepting women as worthwhile peers and bosses, the influence of the unfavorable attitudes of males on organizational decisions concerning woman's career advancement. The result also identifies that the conflict between maternal and work roles are reasons for the slow entry and rise of women in corporate sector.

Cox (1993), in his elaborated work on diversity in organizations explains the importance of managing diversity in workplace. According to him, diversity itself does not automatically have positive effects. It must rather be managed effectively to improve organizational effectiveness. Cox defines the goals of diversity management and discusses the importance of managing diversity in the organizations. He identifies the importance of planning and implementing organizational systems and practices to manage people so that the potential advantages of diversity are maximized while the potential disadvantages are minimized. He uses the term "diversity climate" to define collectively the influence of individual, group and organizational factors that supports diversity in an organization.

\footnotetext{
${ }^{4}$ Dataquest is an IT magazine, published from India.

Present information is collected from the article "TCS, Infosys and Wipro are top Indian IT employers of women" published on $30^{\text {th }}$ January, 2013.Information has been accessed from http://www.dqindia.com/dataquest/feature/173729/tcs-infosys-wipro-indian-it-employers-women.
}

5 NASSCOM, National Association of Software and Services Company, is a strong IT industry lobbying body. This is a trade association of Indian Information Technology (IT) and Business Process Outsourcing (BPO) industry 
Woods and Sciarini, (1995), identify that employers who successfully manage diversity are better at attracting and retaining skills and talent. Because of the efforts incorporated to recognize, and to embrace the diversity in organizations the employers are successfully managing diversity. The study explains, as the economies are shifting from manufacturing to service economies, diversity issues are gaining importance, because in a service economy, effective interactions and communications between people are essential to business success. Employers who adopt diversity can also benefit from cost savings by having a more costeffective recruitment process. The study identifies diversity requires a type of organizational culture in which each employee can pursue his or her career aspirations without being inhibited by gender, race, nationality, religion, or other factors that are irrelevant to performance.

NASSCOM-Mercer, a joint research company, which conducts extensive surveys on IT Industry, performed researches on gender inclusivity in IT Sector. Researches such as "Gender Inclusivity and Diversity in the Indian IT-BPO Industry", (2008), "Gender inclusivity in India: building empowered organizations" (2009) and "Workforce inclusiveness in Indian IT industry" (2009), are few studies reported and give elaborated view of diversity in IT and ITES-BPO industries in India. The reports highlight that India has more working women than any other country in the world. Of the entire workforce of 400 million, 30-35 percent is female, and among these women, only 20 percent work in urban India. This figure can largely be attributed to the growth of the IT-BPO industry, which is one of the largest recruiters of a qualified women workforce in recent times. The reports note that there is no successful gender diversity inclusion in IT companies of India. The reports suggest that the organizations focus on embracing, leveraging and accepting differences for the best possible business outcomes. According to these reports, despite the number of diversity forums, mandated government policies, and widespread discussion in the media, the obstacles to gender diversity continues to remain largely unresolved. The report suggests that the outlook of the society must change in terms of perception that truly integrates women into the workforce in India.

Choi and Rainey (2010) address the effects of diversity and diversity management on employee perceptions of organizational performance in U.S. federal agencies by developing measures of three variables: diversity, diversity management, and perceived organizational performance. Levels of diversity of 67 federal agencies were measured and analyzed to know diversity management affects the relationship between levels of diversity and perceptions of organizational performance. Drawing from the Central Personnel Data file and the 2004 Federal Human Capital Survey, their findings suggest that racial diversity relates negatively to organizational performance. When moderated by diversity management policies and practices and team processes, however, racial diversity correlates positively with organizational performance. The results found that higher levels of gender diversity tend to increase organizational performance when the employees worked together longer. Gender and age diversity and their interactions with contextual variables produce mixed results, suggesting that gender and age diversity reflect more complicated relationships. The study showed how managerial efforts and other contextual factors such as organization culture, demographic characteristics of employees moderate the relationship between diversity and organizational outcomes. Overall the findings show that the effects of diversity may vary according to the types of diversity.

NASSCOM-PWC (2010), reports on 'Diversity in action', explain diversity in Indian organizations by collecting information by doing extensive survey. As per this report, predominant thread of diversity in the Indian context is gender, unlike the west, where cultural diversity is the most dominant thread. Because of diversity inclusion, the companies started to recognize the specific requirements for women, based on the different stages in life. Efforts are being made to proactively support women employees with policies and systems through these phases. Flexible working and extended maternity leave as policy or practice are dependent on the size and business requirements of the organizations. However, in most instances, flexible work is supported by job rotation and alternate career options. The 2011 survey was a gender neutral survey inviting responses from men and women. A total of 408 responses, 197 female and 211 male employees, were received from executives, senior managers, managers, across all levels and age groups. The survey encouraged participants to respond to questions on business rationale, pride, work- life balance, benefit to society, views on diversity practices etc. Most of the respondents, across the gender, agreed that diversity and inclusion has a business rationale for their organization. The disagreements, in the minority, were from respondents at the entry levels from the age group of 25 to 29 years. A small proportion of respondents, predominantly below 30 years of age, felt there was no such benefit. Despite minor disagreements, the majority of the respondents agreed that there is the necessity of fair recruitment process without discrimination with respect to gender diversity and need of facilities and infrastructure support to women.

The research work by Kulik.et al. (2011), studies about a positive relationship between gender diversity and performance. The results show partial support for the positive linear and inverted U-shaped curvilinear predictions as well as for the proposed moderating effect of industry type. The curvilinear relationship indicates that different proportions of organizational gender diversity have different effects on organizational performance, which may be attributed to different dynamics as suggested by the resource-based view and self- 
categorization and social identity theories. The results help reconcile the inconsistent findings of past research that focused on the linear gender diversity performance relationship. The findings also show that industry context can strengthen or weaken the effects of organizational gender diversity on performance.

Williams and O'Reilly (1998), in their research paper, identify managing workforce diversity is one of the most difficult and pressing challenges of modern organizations. They call diversity as "hot-button" issue in corporate, political, and legal circles, as maximizing and capitalizing on workplace diversity has become an important issue for management. Authors identify that the demographic differences like sex, age are conventionally related to team level outcomes. The paper identifies the importance of understanding about the history of diversity management, which gives an idea about the evolution of the interest in a diverse workforce in organizations. The paper explains the need of more interaction among people from diverse cultures, beliefs, and backgrounds to manage diversity. This study explores that managers in public and private organizations should understand, predict and evaluate the nature of the diverse workforce to make diversity initiatives successful in multicultural organizations.

Woodard and Saini (2005) have performed a comparative study of diversity management in USA and Indian organizations. Authors identify much of the diversity management discourse in India is at the stage of equal opportunity. Here too, the gap between the legal promise and actual implementation is very wide. Authors identify that the position of women's rights is not clearly defined in India and authors quote several forms of unfavorable discrimination from society, employers and superiors towards women. Scholars identify masculine and patriarchal, male dominated workplace culture in organizations of India. This paper identifies the presence of stereotypic behaviors against women's independence resulting in further discrimination against them. Thus, traditional patriarchal attitudes towards women still prevail. But, they notice that with the rise in literacy levels and betterment of the position of women due to economic and social development, the position of women in IT industry and in education sector has been improving. Authors identify that there is a greater need of developing diversity researches on diversity inclusive environment and demographic variables across the IT Industry in India.

By exploring these works, it is found that there are many obstacles present to successful inclusion of diversity and there is need for proper diversity management initiatives. By considering the literature, the present study has been conducted to explore the relationship between diversity management practices and obstacles with acceptance of gender diversity in IT organizations.

\subsection{Objectives of the study:}

The objective of the study is to investigate the relationship between acceptance of gender diversity among employees, diversity practices and programs adopted by the organizations and obstacles to gender diversity. The study focuses on several diversity programs and practices, which are commonly adopted in IT industry and examines the influence of these initiatives on the acceptance of gender diversity in industry. The study also identifies the obstacles present in IT industry scenario and examines the influence of these obstacles on the overall acceptance of employees towards gender diversity.

\subsection{Operational Definitions of the variables under investigation}

For the purpose of present study, different terms are operationally defined with reference to diversity climate. Diversity climate is a term (version from Cox, 1993) used in this study to collectively define the influence of individual, group and organizational factors that affect support for diversity in organization.

\subsubsection{Workforce Diversity}

This refers to differences among people based on culture, gender, race, ethnicity, age, religion, educational background, physical and mental disability, and other socio-economic class. For the present study, workforce diversity is operationally limited to gender diversity.

The word acceptance means the action of consenting to receive something offered or the process of receiving something as adequate, valid and salient (Oxford English dictionary). For the present study, acceptance of gender diversity indicates that how the employees of IT industry are receiving with consent to the gender differences, existing in the industry context.

\subsubsection{Acceptance of Gender Diversity}

This variable refers to the perceptions of the employees towards understanding, valuing and accepting gender differences and similarities present in workforce. This explains the employee perceptions of the importance of diversity and their attitudes towards gender diversity. For the purpose of study, accepting the similarities and differences with respect to male and female employees that has been observed at IT Industry, located in Bangalore region have been considered. 


\subsubsection{Obstacles to Gender Diversity}

These refer to the factors which create barriers and problems to gender diversity climate. This variable lists nine different items associated with gender diversity climate in IT industry.

\subsubsection{Gender Diversity Management Programs and Practices}

This refers to organizational interventions designed to facilitate policies, systems and processes that are conducive to employees of different gender groups. Variable explains how strongly programs and practices initiated by the companies to manage gender diversity and lists ten items, which describe the gender diversity management programs and practices adopted in industry.

\subsection{Research Design}

The research adopts both exploratory and descriptive design for structuring the further process. Experts' opinion survey and focus group interview are conducted to get insight into the area of research. HR managers of various IT companies were approached to get opinion about diversity management practices and obstacles present in industry. Focus group interviews among several IT professionals provided valuable feedback of diversity inclusion in IT companies and employee receptivity to the diversity issues. Based on this exploration study, the questionnaire was designed. As used in attitudinal research, a five-point Likert rating scale $^{6}$ was used to record survey responses and these questionnaires were administered among respondents to collect data for the research. In addition, several internal documents were reviewed and numbers of interactions were conducted with HR managers of several IT companies, to supplement information from the survey.

\subsubsection{Sampling population}

A sample of 600 respondents was included in the current study. To collect this data, around 900 questionnaires were administered among employees, constituting both male and female respondents. Out of these, 700 questionnaires were collected with response rate of $77.78 \%$. After examining, 100 responses were eliminated because of the missing data. Finally, 300 responses from employees of 15 IT services companies and 300 responses from employees of 15 ITES-BPO services companies have been included for the study.

\subsubsection{Data Collection}

The Primary data has been collected from IT companies situated at Bangalore. Care has been taken to collect data from 15 IT services companies and 15 ITES-BPO companies situated at different locations of Bangalore. Sample size for the study is 600 . Responses were collected for the present study by personal contact and through e-mails.

Secondary data has been collected by company websites, journals related to Information Technology Industry, websites related to IT companies, and published interviews with top leaders of the industry.

\subsubsection{The Tool}

A detailed questionnaire is designed keeping in view the objectives and objectives of the study and administered among sample respondents.

The questionnaire has four sections:

Section 1: Information regarding the personal information of respondents was sought. It constitutes age group, experience, gender, and marital status of the respondents

Section 2: This section is about acceptance of gender diversity of employees.

The section is about acceptance of gender diversity and 9 items were listed, that explain perceptions of employees towards acceptance of gender diversity. The Items were listed, using 5 point Likert rating scale, ranging from $1=$ strongly disagree, $2=$ disagree, $3=$ neutral, $4=$ agree, $5=$ strongly agree. These items were framed on the basis of the discussion with HR managers of IT companies and are developed by the researcher by referring SHRM survey reports. ${ }^{7}$ The respondents are requested to tick the appropriate box according to their perception.

Section 3 - This section is about obstacles prevailing with respect to gender diversity in IT organizations. This section constitutes 9 items and these items were scaled using 5 point Likert rating scale, ranging, $1=$ very low, $2=$ low, $3=$ medium, $4=$ high, $5=$ very high. This section had been developed on the basis of SHRM survey reports (2005).

\footnotetext{
${ }^{6}$ Likert scale is a scale commonly involved in research that employs questionnaire and is the most widely used approach to scaling responses in survey researches, named after its inventor, psychologist Rensis Likert.

${ }^{7}$ Society for Human Resource Development., 2005, Workplace Diversity Practices Survey Report.
} 
Section 4- This section refers how strongly diversity management programs and practices have been initiated in the organization.

This section lists 10 items related with gender diversity management programs and practices adopted in IT industry. All these items were listed, using five-point Likert rating scale, ranging from 1=strongly disagree, $2=$ disagree, $3=$ neutral, $4=$ agree, $5=$ strongly agree. These items were framed on the basis of discussion with the HR managers from various IT companies and reference has been taken from Tripartite Alliance for Fair Employment Practices diversity scale. ${ }^{8}$

The secondary data was collected from IT journals, research papers, company profiles, documents and records and from company websites. A pilot test was conducted to test the reliability of the questionnaire.

\subsubsection{Data analysis}

Data collected from extensive survey is analyzed and interpreted. The analysis of data was done using following statistical tools.

1. Pearson's correlations

2. Chronbach's alpha for reliability test

3. Multiple regression analysis.

The Chronbach's alpha coefficient for the pilot test and for the total sample were obtained and values range from 0.81 to 0.86 , indicating a high level of inter item consistency for the variables.

Based on the objectives and premises of the study, two hypotheses were framed for the empirical testing.

\subsubsection{Hypotheses}

Based on the objectives and premises of the study two hypotheses were formed to investigate scientifically. H1: There is significant relationship between acceptance of gender diversity and gender diversity management programs and practices.

H2: There is significant relationship between acceptance of gender diversity and obstacles to gender diversity. The analysis was done using the statistical analysis tool SPSS (Statistical Package for Social Science), version 16.

\subsubsection{Statistical tools}

Two hypotheses are generated for the study as stated above. These hypotheses were subjected to empirical test by using different statistical tools as explained, viz: Pearson correlations and multiple regression analysis to test the hypotheses 1 and 2.

\subsection{General sample profile}

The general information of the sample that has been taken for the present study is described in detail.

Frequency distributions and percentage of the sample profile is explained through descriptive statistics.

\subsubsection{Descriptive statistics: Frequency distribution}

Frequency distributions were obtained for all the personal data of the sample profile variables. The frequencies for the number of employees categorized as type of company [Table 1.1], years of experience [Table 1.2], age [Table 1.3], gender [Table 1.4] and marital status [Table 1.5] are shown below.

Table 1.1: Frequency and percentage of employees with respect to type of company

\begin{tabular}{|l|l|l|l|l|}
\hline Type of the company & Frequency & Percent & $\begin{array}{l}\text { Valid } \\
\text { Percent }\end{array}$ & $\begin{array}{l}\text { Cumulative } \\
\text { Percent }\end{array}$ \\
\hline IT-Services & 300 & 50.0 & 50.0 & 50.0 \\
\hline ITES-BPO-Services & 300 & 50.0 & 50.0 & 100.0 \\
\hline Total & 600 & 100.0 & 100.0 & \\
\hline
\end{tabular}

\section{Experience of the respondents:}

Table 1.2: Experience of employees in company

\begin{tabular}{|l|c|c|c|c|}
\hline $\begin{array}{l}\text { Experience of } \\
\text { Employees }\end{array}$ & Frequency & Percent & $\begin{array}{l}\text { Valid } \\
\text { Percent }\end{array}$ & $\begin{array}{l}\text { Cumulative } \\
\text { Percent }\end{array}$ \\
\hline Below 2 years & 108 & 18.0 & 18.0 & 18.0 \\
\hline 2-5 years & 160 & 26.7 & 26.7 & 44.7 \\
\hline 6-10 years & 176 & 29.3 & 29.3 & 74.0 \\
\hline
\end{tabular}

\footnotetext{
${ }^{8}$ Popularly known as TAFEP, which was set up to promote adoption of non-discriminatory and responsible employment practices among employers, employees and the general public, Singapore.
} 
Workforce diversity and management: An emphirical study on relationship between diversity.....

\begin{tabular}{|l|c|c|c|c|}
\hline $11-15$ years & 89 & 14.8 & 14.8 & 88.8 \\
\hline 16 years and above & 67 & 11.2 & 11.2 & 100.0 \\
\hline Total & 600 & 100.0 & 100.0 & \\
\hline
\end{tabular}

Age:

Table 1.3: Age group of employees

\begin{tabular}{|l|c|c|c|c|}
\hline $\begin{array}{l}\text { Age of } \\
\text { employees }\end{array}$ & Frequency & Percent & $\begin{array}{l}\text { Valid } \\
\text { Percent }\end{array}$ & $\begin{array}{l}\text { Cumulative } \\
\text { Percent }\end{array}$ \\
\hline Below 25 & 106 & 17.7 & 17.7 & 17.7 \\
\hline $25-29$ & 195 & 32.5 & 32.5 & 50.2 \\
\hline $30-35$ & 163 & 27.2 & 27.2 & 77.3 \\
\hline 36 and above & 136 & 22.7 & 22.7 & 100.0 \\
\hline Total & 600 & 100.0 & 100.0 & \\
\hline
\end{tabular}

Gender:

Table 1.4: Frequency and percentage of employees with respect to gender

\begin{tabular}{|l|c|c|c|c|}
\hline $\begin{array}{l}\text { Gender of } \\
\text { employees }\end{array}$ & Frequency & Percent & $\begin{array}{l}\text { Valid } \\
\text { Percent }\end{array}$ & $\begin{array}{l}\text { Cumulative } \\
\text { Percent }\end{array}$ \\
\hline Male & 337 & 56.2 & 56.2 & 56.2 \\
\hline Female & 263 & 43.8 & 43.8 & 100.0 \\
\hline Total & 600 & 100.0 & 100.0 & \\
\hline
\end{tabular}

Marital Status:

Table 1.5: Frequency and percentage of employees with respect to marital status

\begin{tabular}{|l|c|c|c|c|}
\hline $\begin{array}{l}\text { Marital status of } \\
\text { Employees }\end{array}$ & Frequency & Percent & $\begin{array}{l}\text { Valid } \\
\text { Percent }\end{array}$ & $\begin{array}{l}\text { Cumulative } \\
\text { Percent }\end{array}$ \\
\hline Single & 271 & 45.2 & 45.2 & 45.2 \\
\hline Married & 319 & 53.2 & 53.2 & 98.3 \\
\hline $\begin{array}{l}\text { Others (divorced, } \\
\text { widow, widower etc.) }\end{array}$ & 10 & 1.7 & 1.7 & 100.0 \\
\hline Total & 600 & 100.0 & 100.0 & \\
\hline
\end{tabular}

\subsubsection{Descriptive statistics for acceptance of gender diversity}

The dependent variable acceptance of gender diversity has been explained by 9 items. Mean and standard deviation for each item has been listed in table 1.6, and represented through the graph 1.1. This table explains the response of sample respondents with respect to each item, which indicate the acceptance of gender diversity.

Table 1.6: Descriptive statistics for variable acceptance of gender diversity

\begin{tabular}{|l|l|c|c|}
\hline \multicolumn{1}{|c|}{ Items } & $\mathbf{N}$ & Mean & Standard Deviation \\
\hline Comfortable to work in a group where there are both male and females & 600 & 4.38 & 0.62 \\
\hline Value others regardless of their gender, dress and mannerisms & 600 & 4.2 & 0.51 \\
\hline Communicate effectively regardless of gender differences & 600 & 4.18 & 0.50 \\
\hline Can learn new skills, values by working with the people of other gender & 600 & 4.23 & 0.66 \\
\hline Gender quota policy is necessary from recruitment to retainment & 600 & 3.35 & 1.17 \\
\hline Value and respect fundamental differences with respect to gender & 600 & 4.24 & 0.59 \\
\hline Comfortable to work with boss regardless of gender consideration & 600 & 4.12 & 0.47 \\
\hline Gender diversity is very important to organization & 600 & 3.21 & 1.33 \\
\hline No difference in work performance in workplace by both gender & 600 & 3.97 & 0.99 \\
\hline Valid N (listwise) & 600 & & \\
\hline
\end{tabular}


Graph 1.1: Acceptance of gender diversity.

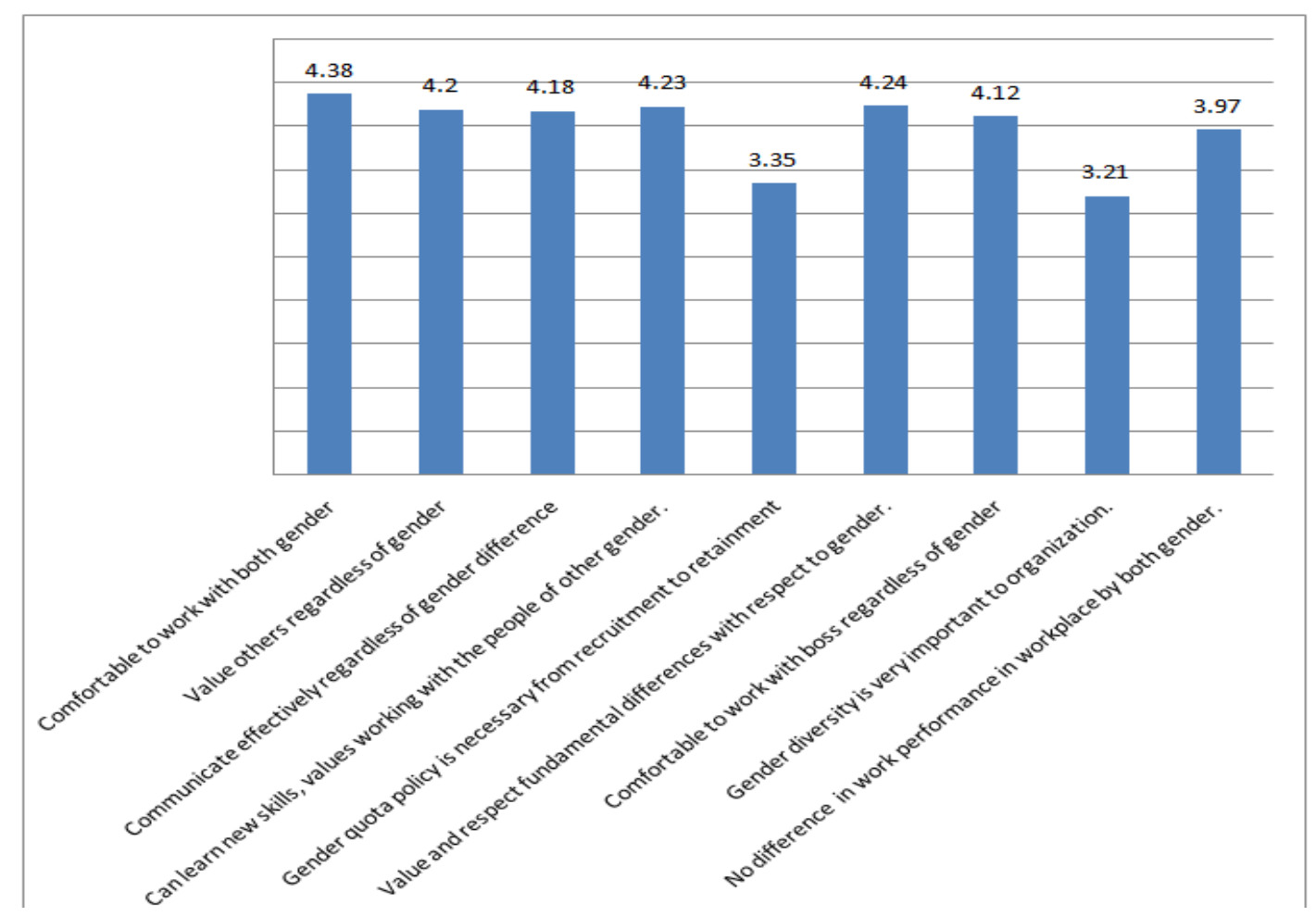

Interpretation: The Table 1.6 and graph 1.1 explain the item wise responses for employees towards acceptance of gender diversity in organizations. The mean and standard deviation for the responses for every item is calculated. Results indicate that respondents are very much comfortable to work in a group where there are both male and females (mean $=4.38$ ), and their perception towards valuing the colleagues irrespective of their gender is also very much positive (mean $=4.2$ ). Respondents agree to the statement that they communicate effectively regardless of gender differences (mean $=4.18$ ), they are positive to the statement that they will learn new skills by working with other gender (mean $=4.2)$. Respondents agree that they value fundamental differences, regardless of differences in gender (mean $=4.2$ ), and their response in being comfortable to work under boss regardless of gender is also positive (4.1). Respondents also agree that there will be no difference in work performance regardless of gender differences (mean $=3.97$ ). Comparative to the responses to all the statements, surprisingly the respondents' acceptability to the two items is very low, ie, gender diversity is very important to the organization is (mean $=3.20)$, and, gender quota policy is necessary in organization $($ mean $=3.3)$. The results indicate that respondents are almost neutral to the statement which states that gender diversity is very important to the organization (mean $=3.20$, and standard deviation $=1.33$ ), and gender quota policy is necessary from recruitment to retainment in organizations (mean $=3.35$, standard deviation $=1.17$ ), indicating the responses for these statements are slightly deviating from the mean and are not consistent. From the above results, it can be interpreted that, though respondents are accepting the gender diversity, they are not agreeing that gender diversity is very important to the organization. The respondents are not positively agreeing that the gender quota policy is necessary in organizations. The overall mean for all the items of acceptance of gender diversity is 3.99 ,

\subsubsection{Descriptive statistics for variable obstacles to gender diversity}

The nine items describe independent variable obstacles to gender diversity Table 1.7 and graph 1.2 represent the response of total 600 employees in IT industry. Overall nine items describe obstacles to gender diversity.

Table 1.7: Descriptive statistics for variable obstacles to gender diversity

\begin{tabular}{|l|l|l|l|}
\hline \multicolumn{1}{|c|}{ Items } & N & Mean & $\begin{array}{c}\text { Std. } \\
\text { Deviation }\end{array}$ \\
\hline Stereotype & 600 & 3.06 & 1.42 \\
\hline
\end{tabular}


Workforce diversity and management: An emphirical study on relationship between diversity.....

\begin{tabular}{|l|l|l|l|}
\hline Sexual harassments and abuses & 600 & 2.16 & 1.45 \\
\hline Work life balance problems & 600 & 3.60 & 1.13 \\
\hline Masculine/Patriarchal corporate culture & 600 & 3.01 & 0.94 \\
\hline Lack of flexible work solutions & 600 & 2.95 & 0.98 \\
\hline Lack of adequate information about existing diversity policies and practices & 600 & 2.16 & 0.94 \\
\hline Lack of leadership commitment to diversity & 600 & 2.62 & 1.19 \\
\hline Lack of opportunities for higher positions to female employees & 600 & 2.59 & 1.19 \\
\hline Discrimination in promotions and career development opportunities & 600 & 1.98 & 0.80 \\
\hline Valid N (listwise) & 600 & & \\
\hline
\end{tabular}

Graph 1.2: Obstacles to gender diversity

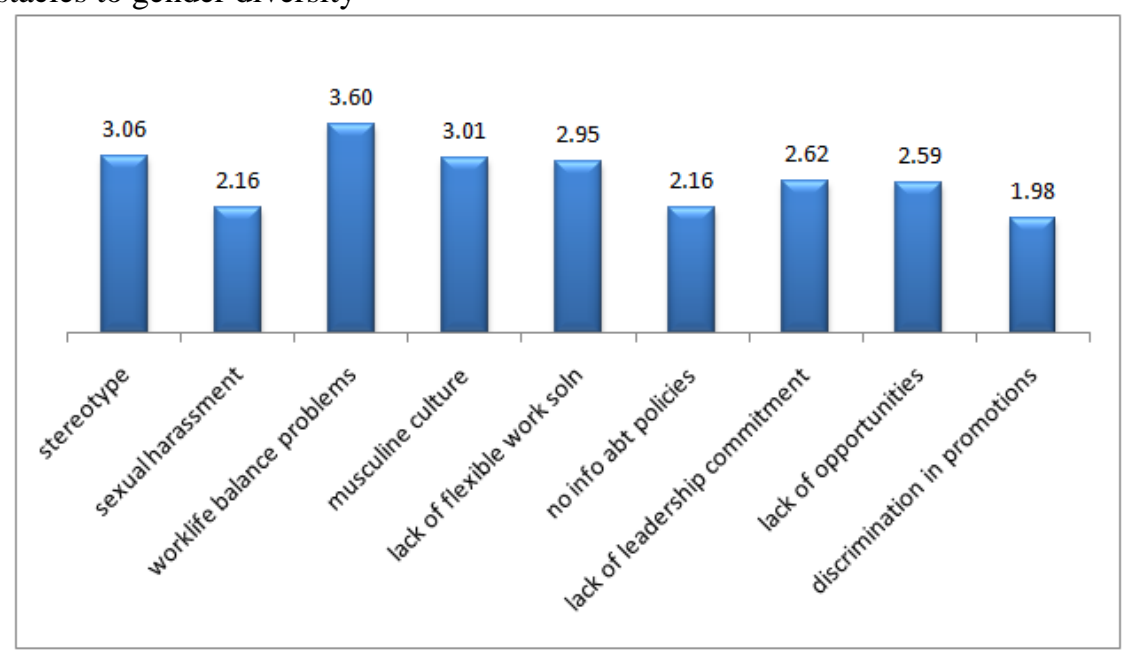

Interpretation: The table 1.7 and graph 1.2 explain the perception of the respondents about how high are the obstacles to gender diversity in organizations. The mean value with standard deviation for the nine different obstacles is calculated to find out how severely they are perceived by the respondents. Results show that respondents opine that there is low discrimination in promotions and career development opportunities (mean $=1.9$ ), and the problems of sexual harassments and abuses are also low (mean =1.6). According to the results, it can be interpreted that the problems like stereotype and work life balance problems for female employees is comparatively high (mean $=3.1, \&$ mean $=3.61$ respectively), and these are the prominent obstacles to gender diversity. Another very important obstacle perceived is the masculine/patriarchal dominating corporate culture (mean $=3.01)$. It is found that there is lack of adequate information about existing diversity policies $($ mean $=$ 2.16), indicating the need for rigorous awareness training. Respondents also feel the problems related to lack of leadership commitment to diversity (mean $=2.62$ ) and lack of opportunities for higher positions to female employees (mean $=2.59$ ). The standard deviations for majority of the items are slightly high indicating the responses are not consistent and slightly deviated from the mean values. Thus, it can be interpreted that employees perceive medium level of obstacles to gender diversity in organizations.

\subsubsection{Descriptive statistics for gender diversity management programs and practices}

10 items describe the gender diversity management programs and practices. The mean and standard deviation represent the overall response of sample respondents towards how highly gender diversity management programs and practices are adopted in IT companies.

Table 1.8: Descriptive statistics for gender diversity management programs and practices

\begin{tabular}{|l|l|l|l|}
\hline \multicolumn{1}{|c|}{ Items } & \multicolumn{1}{|c|}{$\mathrm{N}$} & \multicolumn{1}{|c|}{ Mean } & $\begin{array}{l}\text { Standard. } \\
\text { Deviation }\end{array}$ \\
\hline $\begin{array}{l}\text { Diversity training sessions are conducted to enhance awareness about } \\
\text { gender equality and to remove gender bias issues }\end{array}$ & 600 & 3.67 & 0.64 \\
\hline $\begin{array}{l}\text { Mentoring coaching and counseling sessions are there for career } \\
\text { development and in taking responsibility to female employees }\end{array}$ & 600 & 4.10 & 0.66 \\
\hline $\begin{array}{l}\text { There are options for flexible working hours (e.g. work from home, } \\
\text { part time work, flexible timings) }\end{array}$ & 600 & 4.01 & 1.10 \\
\hline Supports female networking forum, affinity groups & 600 & 4.15 & 0.59 \\
\hline
\end{tabular}


Workforce diversity and management: An emphirical study on relationship between diversity.....

\begin{tabular}{|l|l|l|l|}
\hline Conducts diversity workshops and seminars & 600 & 3.77 & 0.70 \\
\hline $\begin{array}{l}\text { There are policies about smooth transition before, during and after } \\
\text { parental leave at the time of childbirth and childcare }\end{array}$ & 600 & 3.78 & 0.74 \\
\hline There is protection against mobbing and sexual harassment & 600 & 4.40 & 0.58 \\
\hline $\begin{array}{l}\text { There are policies which favor gender quota in hiring, promoting, } \\
\text { retaining and development }\end{array}$ & 600 & 3.14 & 0.83 \\
\hline There is protection against gender discrimination & 600 & 3.24 & 0.74 \\
\hline $\begin{array}{l}\text { There is enough funding, involvement and commitment by top leaders } \\
\text { gender diversity programs }\end{array}$ & 600 & 4.19 & 0.64 \\
\hline Valid N (listwise) & 600 & & \\
\hline
\end{tabular}

Graph 1.3: Gender diversity management programs and practices

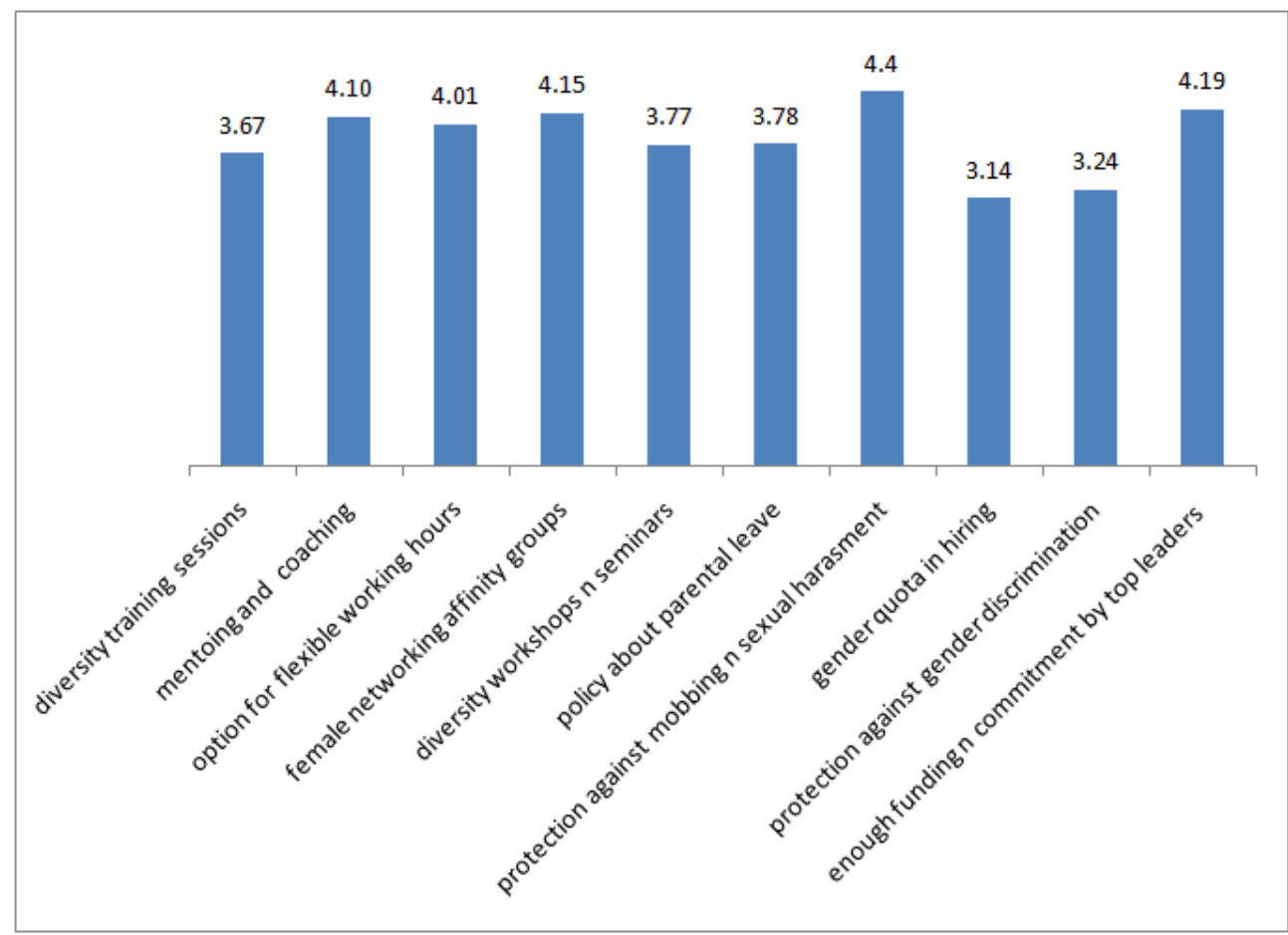

Interpretation: The table 1.8 and graph 1.3 show the response of respondents about how strongly gender diversity management programs and practices have been initiated in organizations. It has been found that employees highly agree that the practice of mentoring and coaching and counseling (mean $=4.10$ ), option for flexible working hours (mean $=4.01$ ), female networking and affinity groups (mean $=4.15$ ) and policies for protection against mobbing and sexual harassment $($ mean $=4.4$ ) have been very well initiated by companies to manage gender diversity. Further, employees agree that there is enough funding and commitment by top leaders towards gender diversity programs and practices $($ mean $=4.2)$. Respondents almost agree that there is practice of conducting diversity workshops and seminars (mean $=3.77$ ) and there is policy for parental leave at the time of childbirth and childcare (mean $=3.78$ ). But, respondents are almost neutral about certain practices like gender quota in hiring, promoting, retaining and development (mean $=3.14)$, and protection against gender discrimination (mean $=3.24$ ), which indicates that the practice of gender quota in HR functions has not been implemented properly and employees are not happy with the policies towards protection against gender discrimination.

\subsection{Hypotheses testing}

To test the hypotheses, a description of variables under investigation will be restated below, and hypotheses were tested using appropriate statistical tools.

\subsubsection{Variables under investigation}

i. Independent variables:

- $\quad$ Gender diversity management programs and practices

- $\quad$ Obstacles to gender diversity 
ii. Dependent variable:

- $\quad$ Acceptance of gender diversity

\subsubsection{Hypotheses under investigation}

To test these hypotheses, null hypothesis and alternate hypothesis were framed as follows.

$\mathrm{H} 1_{0}$ : There is no significant relationship between acceptance of gender diversity and gender diversity management programs and practices.

$\mathrm{H} 1_{\mathrm{A}}$ : There is significant relationship between acceptance of gender diversity and gender diversity programs and practices.

$\mathrm{H} 2_{0}$ : There is no significant relationship between acceptance of gender diversity and obstacles to gender diversity.

$\mathrm{H} 2_{\mathrm{A}}$ : There is significant relationship between acceptance of gender diversity and obstacles to gender diversity.

Table 1.9: Correlation coefficients for variables:

\section{Correlations}

\begin{tabular}{|c|c|c|c|c|}
\hline & & $\begin{array}{l}\text { Acceptance of } \\
\text { gender diversity }\end{array}$ & $\begin{array}{l}\text { Obstacles to } \\
\text { gender diversity }\end{array}$ & $\begin{array}{c}\text { Gender diversity } \\
\text { management programs and } \\
\text { practices }\end{array}$ \\
\hline \multirow{3}{*}{$\begin{array}{l}\text { Acceptance of gender } \\
\text { diversity }\end{array}$} & $\begin{array}{l}\text { Pearson } \\
\text { Correlation }\end{array}$ & 1 & $-0.690^{* *}$ & $0.200^{* *}$ \\
\hline & Sig. (2-tailed) & & 0.000 & 0.000 \\
\hline & $\mathrm{N}$ & 600 & 600 & 600 \\
\hline \multirow{3}{*}{ Obstacles to gender diversity } & $\begin{array}{c}\text { Pearson } \\
\text { Correlation }\end{array}$ & $-0.690^{* *}$ & 1 & $0.372^{* *}$ \\
\hline & Sig. (2-tailed) & 0.000 & & 0.000 \\
\hline & $\mathrm{N}$ & 600 & 600 & 600 \\
\hline \multirow{3}{*}{$\begin{array}{c}\text { Gender diversity } \\
\text { management programs and } \\
\text { practices }\end{array}$} & $\begin{array}{c}\text { Pearson } \\
\text { Correlation }\end{array}$ & $0.200^{* *}$ & $0.372^{* *}$ & 1 \\
\hline & Sig. (2-tailed) & 0.000 & 0.000 & \\
\hline & $\mathrm{N}$ & 600 & 600 & 600 \\
\hline
\end{tabular}

**. Correlation is significant at the 0.01 level (2-tailed).

Table 1.10: Regression model summary for cultural diversity programs, obstacles to cultural diversity on

\begin{tabular}{|c|c|c|c|c|c|c|}
\hline \multicolumn{7}{|c|}{ Variables entered } \\
\hline HFonct & valiades cilcted & removed & & In square & $\mathrm{R}$ Square & the Estimate \\
\hline & Gender diversity programs and & \multirow[t]{2}{*}{----} & \multirow[b]{2}{*}{$0.693^{\mathrm{a}}$} & \multirow[b]{2}{*}{0.480} & \multirow[b]{2}{*}{0.479} & \multirow[b]{2}{*}{0.27771} \\
\hline & Obstacles to gender diversity & & & & & \\
\hline
\end{tabular}

a. Predictors: (Constant), Gender div mgmt programs and practices, obstacles to gender diversity

Table 1.11: ANOVA outcome for acceptance of gender diversity

\begin{tabular}{|l|l|c|c|c|c|c|}
\hline \multicolumn{2}{|l|}{ Model } & $\begin{array}{c}\text { Sum of } \\
\text { Squares }\end{array}$ & df & Mean Square & F & Sig. \\
\hline \multirow{2}{*}{$\mathbf{2}$} & Regression & 42.556 & 2 & 21.278 & 275.889 & $.000^{\mathrm{a}}$ \\
\cline { 2 - 7 } & Residual & 46.043 & 597 & .077 & & \\
\cline { 2 - 7 } & Total & 88.599 & 599 & & & \\
\hline
\end{tabular}

a. Predictors: (Constant), Gender div mgmt programs and practices, obstacles to gender diversity 
b. Dependent Variable: Acceptance of gender diversity

Table 1.12: Coefficients

\begin{tabular}{|l|r|r|r|r|r|}
\hline \multirow{2}{*}{ Model 2 } & \multicolumn{2}{l|l|}{$\begin{array}{l}\text { Unstandardized } \\
\text { Coefficients }\end{array}$} & $\begin{array}{l}\text { Standardized } \\
\text { Coefficients }\end{array}$ & & \\
\cline { 2 - 7 } & \multicolumn{1}{|l}{ B } & \multicolumn{1}{l|}{ Std. Error } & Beta & t & \multicolumn{1}{l|}{ Sig. } \\
\hline (Constant) & 4.741 & 0.170 & & 27.901 & 0.000 \\
\hline $\begin{array}{l}\text { Gender diversity mgmt programs and } \\
\text { practices }\end{array}$ & 0.096 & 0.046 & 0.066 & 2.067 & 0.039 \\
\hline Obstacles to gender diversity & -0.429 & 0.019 & -0.615 & -22.489 & 0.000 \\
\hline
\end{tabular}

a. Dependent Variable: Acceptance of gender diversity

Discussion: The Pearson correlation matrix obtained for the three variables is shown in output table 1.9. From the results, we see that the acceptance to gender diversity is negatively correlated to obstacles to gender diversity and is significant. The acceptance of gender diversity is positively and significantly correlated to gender diversity management programs and practices. This indicates that higher diversity programs will result with higher acceptance, after controlling other variable (obstacles). In the same way, higher obstacles will result in lower acceptance, considering control over other variable (diversity management programs).

The regression analysis has been explained by the other three tables 1.10,1.11 and 1.12. Regression model summary is shown through table 1.10 , and $\mathrm{R}$ value (0.693) is the correlation of these two variables with the dependent variable. The model explains $48 \%$ of the variation (value of $R$ square is 0.480 ).

The ANOVA table [table 1.11] shows that the $F$ value is 275.89 and is significant ( $p$-value is 0.000 and is lower than 0.05). In the $d f$ (degree of freedom) column of the same table, the first number represents the number of variables (2), the second number (599) is the total number of complete responses for all the items $(\mathrm{N})$, minus the number of items $(\mathrm{K})$ minus 1. $[(\mathrm{N}-\mathrm{K}-1)=599]$. The $\mathrm{F}$ statistic produced $(\mathrm{F}=275.89)$ is significant at the 0.00 level. This implies that model is significant fit.

Thus, both the null hypotheses were rejected.

Hence, we can interpret that, there is significant relationship between acceptance of gender diversity and gender diversity programs and practices.

And there is significant relationship between acceptance of gender diversity and obstacles to gender diversity.

The table 1.12 shows influence of independent variables on dependent variable. If we look beta coefficients, we see that highest number is 0.615 for obstacles to gender diversity, which is significant at 0.000 level. This implies that gender diversity management practices and obstacles are significantly influencing acceptance of gender diversity (Beta values are 0.066 and $-0.615, p<0.05$ and $t> \pm 1.96$ ). Gender diversity obstacles are influencing higher than gender diversity management programs and practices. Obstacles to gender diversity have significant negative effect on acceptance of gender diversity among employees.

From this regression model, constant value is 4.741 and coefficients obtained are 0.096 and -0.429 for independent variables. The regression equation can be estimated as,

$\mathrm{Y}_{1}=4.741+(0.096) \mathrm{X}_{1}-(0.429) \mathrm{X}_{2}$

Where $Y_{1}=$ Acceptance of gender diversity (Dependent variable);

$\mathrm{X}_{1}=$ Gender diversity management programs and practices (Independent variable);

$\mathrm{X}_{2}=$ Obstacles to gender diversity (Independent variable).

This regression equation provides a clear view of the relationship between gender diversity management programs and obstacles to diversity. More and more gender diversity management programs will have a positive and significant influence on acceptance of gender diversity in organizations. The model explains that obstacles have more negative influence on acceptance of gender diversity in organizations. Thus, employers should focus on minimizing the obstacles present in organizations to enhance the affectivity of gender diversity acceptance in organizations.

\section{Conclusion}

Diversity management is concerned with attracting the widest possible range of employees, treating all members of the workforce as an asset, and making best use of their potential in order to maximize the capacity of the organization and, simultaneously, the more acceptance of diversity among the employees. In seeking to respect, value and accept the diversity in organizations, employers should recognize the importance of diversity management programs and practices to be adopted in organizations. The results of this study had given important consideration on obstacles to diversity and diversity management programs and practices in IT 
Workforce diversity and management: An emphirical study on relationship between diversity.....

industry. The relationship between obstacles and acceptance of diversity is significant and obstacles have very high negative influence on acceptance of diversity among employees. The analysis to find out the relationship between diversity management practices and acceptance showed that there is significant relationship between the two and diversity management efforts have positive impact on acceptance of diversity. Two regression models were also derived on basis of results, which explain the relationship between acceptance of diversity, obstacles, and diversity management initiatives.

\section{References}

[1] Bhatnagar, Deepthi (1987), “A study of attitudes towards women managers in Banks", Working Paper, No. 1987/668, Indian Institute of Management, Ahmadabad.

[2] Barney, J., Wright, M., Ketchen, D.J.(2001), "The resource-based view of the firm: Ten years after 1991", Journal of Management, Special issue, Vol 27, pp. 625-641

[3] Cox, T. (1991), "Managing Cultural Diversity: Implications for Organizational Competitiveness", Academy of Management, Vol. 5 (3), pp. 45-56.

[4] - (1993), “Cultural Diversity in Organizations: Theory, Research and Practice”. San Francisco, Berrett-Koehler

[5] Choi and Rainey (2010) "Managing Diversity in U.S. Federal Agencies: Effects of Diversity and Diversity Management on Employee Perceptions of Organizational Performance", Public Administration Review, Vol 70 (1), pp.109-121.

[6] Dataquest ,"The Gender Debate", online published on 24 August, 2009, retrieved from www.dqindia.com

[7] --.-"TCS, Infosys and Wipro are top Indian IT employers of women" published on 30 3 th January, 2013. Information has been accessed from http://www.dqindia.com/dataquest/feature/173729/tcs-infosys-wipro-indian-it-employers-women.

[8] ---------- "TCS, Infosys and Wipro are top Indian IT employers of women", online published on 30 January, 2013, retrieved from www.dqindia.com.

[9] Dobbs, M. F. (1996), "Managing Diversity: Lessons from the Private Sector", Public Personnel Management”, 25(3), pp. 351-367

[10] Dora and Kieth (1998), "Demographic diversity and faultiness: The compositional dynamics of organizational groups", Academy of Management Review, Vol 23 (2), pp. 325-340

[11] Ely, R., and Thomas, D (2001), "Cultural diversity at work: The effects of diversity perspectives on work group processes and outcomes", Administrative Science Quarterly, 46(2), 229-273

[12] Esty, Katharine, Richard Griffin, and Marcie Schor-Hirsh. (1995), Workplace diversity. A manager's guide to solving problems and turning diversity into a competitive advantage. Avon Publishers.

[13] Khandelwal, P. (2002), "Gender Stereotypes at Work: Implications for Organizations", Indian journal of Training and Development, Vol. 32, No. 2. (April - June), pp. 72-83.

[14] Kundu, S C and Turan, M S, (1999). "Managing Cultural Diversity in Future Organizations", The Journal of Indian Management and Strategy, Vol. 4 (1), pp. 61-72

[15] Kulik, A.M., C.T., Metz, I.(2011), "The gender diversity performance relationship in services and manufacturing organizations", The International Journal of Human Resource Management, Vol 22,(7), pp.1464-1485

[16] Milliken, F. J., Martins, L.L. (1996), "Searching for common threads: Understanding the multiple effects of diversity in organizational groups", Academy of Management Review, 21, pp. 402-403

[17] NASSCOM Strategic Review, 2012, retrieved from www.nasscom,in

[18] NASSCOM \& Mercer Report "Gender Inclusivity and Diversity in the Indian IT-BPO Industry", (2008), and "Gender inclusivity in India: building empowered organizations” (2009).

[19] NASSCOM-PWC Survey Report which constitutes, "The corporate awards for excellence in diversity among IT/ITES companies of India" and NASSCOM-PWC Report. (2001), "Changing landscape and emerging trends, Indian IT/ITES Industry", (www.pwc.com/India )

[20] O'leary, B.J. and Weathington (2006), "Beyond the Business Case for Diversity", Employee Response Rights Journal, 18, pp. 283292.

[21] Schwind, H., Das, H., \& Wagar T. (2007). "Diversity management”. In H. Schwind, H. Das, \& T. Wagar (Eds.), “Canadian Human resource management: A strategic approach" (8th ed.), 486-524. Toronto: McGraw-Hill Ryerson

[22] Thomas, R. R (1991), "Beyond Race and Gender". AMACOM, New York

[23] -------- (1991), Managing Diversity: A Strategic Opportunity: The Municipal Year Book. Washington, DC, International City Management Association, pp. 24-28.

[24] Thomas Kochan., Katerina Bezrukova, Robin Ely, Susan Jackson, Aparna Joshi, Karen Jehn, Jonathan Leonard, David Levine, and David Thomas. (2003), "The Effects of Diversity on Business Performance: Report of the Diversity Research Network", Human Resource Management, spring, Vol 42 (1), pp. 3-21

[25] Wentling, R.M., \& Palma-Rivas, N. (1998). "Current Status and Future Trends of Diversity Initiatives in the Workplace: Diversity Experts' perspective". Human Resource Development Quarterly, Vol 9 (3), pp. 235-253.

[26] Williams and O'Reilly (1998), "Demography and diversity in organizations: A review of 40 years of research". Research in Organization Behavior, Vol 20, pp. 77-140.

[27] Woods, R.H. and Sciarini, M.P. (1995) "Diversity programs in chain restaurants", Cornell Hotel and Restaurant Administration Quarterly. Vol.36 (3), June.pp.18-23.

[28] Woodard, N. \& Debi S Saini (2005) "Diversity Management Issues in USA and India: Some Emerging Prospectives", (Eds): Pritham Singh, Jyotsna Bhatnagar, Asha Bhandarkar in book, "Future of work, mastering change", Excel Publishers. 